\title{
Symptomatic Diverticular Disease in Patients With Severely Reduced Kidney Function: Higher Rates of Complications and Transfusion Requirement
}

\author{
Ahmed Dirweesh ${ }^{\mathrm{a}, \mathrm{c}}$, Afolarin Amodu ${ }^{\mathrm{a}}$, Muhammad Khan ${ }^{\mathrm{a}}$, Ritika Zijoo ${ }^{\mathrm{a}}$, Bushra Ambreen ${ }^{\mathrm{a}}$, \\ Mohammad Ibrahim ${ }^{\mathrm{a}}$, Muhammad Ijaz ${ }^{\mathrm{a}}$, Abdelhameed Nawwar ${ }^{\mathrm{a}}$, Kareem Genena ${ }^{\mathrm{a}}$, \\ Muhammad Tahir ${ }^{\mathrm{a}}$, Naresh Kumar ${ }^{\mathrm{a}}$, Vincent A. Debari ${ }^{\mathrm{b}}$, Sara Wallach ${ }^{\mathrm{a}}$
}

\begin{abstract}
Background: The prevalence of diverticulosis is increasing with $5-10 \%$ of patients developing diverticulitis and $5-15 \%$ developing symptomatic bleeding. Diverticulitis can result in abscess, perforation, fistula, or obstruction. Bleeding has combined morbidity and mortality rates of $10-20 \%$. The purpose of this study was to compare diverticulitis-related complications and transfusion requirements for diverticular bleeding in patients with normal to moderately reduced kidney function (glomerular filtration rate (GFR) $\geq 30 \mathrm{~mL} / \mathrm{min} / 1.73$ $\mathrm{m}^{2}$ ) and patients with severe renal impairment (GFR $<30 \mathrm{~mL} /$ $\mathrm{min} / 1.73 \mathrm{~m}^{2}$ ), and identify factors associated with these outcomes.
\end{abstract}

Methods: We retrospectively reviewed records of all patients with diverticulitis and diverticular bleeding treated at our hospital from January 1, 2011 to July 31, 2016. Patients were evaluated for baseline characteristics, GFR, baseline hemoglobin, medications, comorbidities, length of stay (LOS), presence of perforations or abscesses and the need for transfusion.

Results: Of the 291 patients included, males were 167 (58\%). Perforations and abscesses complicating diverticulitis developed in 31/136 $(23 \%)$ of patients with GFR $\geq 30 \mathrm{~mL} / \mathrm{min} / 1.73 \mathrm{~m}^{2}$, and in $13 / 26$ $(50 \%)$ of patients with GFR $<30 \mathrm{~mL} / \mathrm{min} / 1.73 \mathrm{~m}^{2}$ (odds ratio (OR): 3.4; $95 \%$ confidence interval $(\mathrm{CI}): 1.423-8.06 ; \mathrm{P}=0.0073)$. Mean LOS (days) was $6.3 \pm 4$ in the GFR $\geq 30 \mathrm{~mL} / \mathrm{min} / 1.73 \mathrm{~m}^{2}$ group and $8.5 \pm 4.4$ in GFR $<30 \mathrm{~mL} / \mathrm{min} / 1.73 \mathrm{~m}^{2}$ group $(\mathrm{P}=0.0001)$. Blood transfusion for diverticular bleeding occurred in $11 / 78(14 \%)$ of patients with GFR $\geq 30 \mathrm{~mL} / \mathrm{min} / 1.73 \mathrm{~m}^{2}$ and in $22 / 51$ (43\%) of patients with GFR $<30 \mathrm{~mL} / \mathrm{min} / 1.73 \mathrm{~m}^{2}$ (OR: 4.6; 95\% CI: 1.99 - 10.76; P $=0.0004)$. Among patients who needed transfusion, mean LOS was $8.5 \pm 2.5 \mathrm{in} \mathrm{GFR} \geq 30 \mathrm{~mL} / \mathrm{min} / 1.73 \mathrm{~m}^{2}$ group and $9 \pm 5$ in those with

Manuscript accepted for publication February 01, 2017

aDepartment of Internal Medicine, Seton Hall University, Saint Francis Medical Center, Trenton, NJ, USA

bepartment of Internal Medicine, School of Health and Medical Sciences, Seton Hall University, South Orange, NJ, USA

${ }^{\mathrm{c} C}$ Corresponding Author: Ahmed Dirweesh, Department of Internal Medicine, Seton Hall University, Saint Francis Medical Center, Trenton, NJ, USA. Email: adirweesh@stfrancismedical.org

doi: https://doi.org/10.14740/gr784w
GFR $<30 \mathrm{~mL} / \mathrm{min} / 1.73 \mathrm{~m}^{2}(\mathrm{P}=0.04)$. There were no differences in age, gender or race between the study groups.

Conclusion: There was a significant increase in complicated diverticulitis cases, transfusion requirements for diverticular bleeding and LOS in patients with severely reduced kidney function compared to patients with normal-moderately reduced renal function.

Keywords: Diverticulitis; Bleeding; Renal failure; GFR

\section{Introduction}

Colonic diverticular disease is an important cause of hospital admissions and a costly digestive disorder in Western and industrialized communities $[1,2]$. The prevalence of diverticulosis increases with age from less than $20 \%$ at age 40 to $60 \%$ by age 60 [3].

Complications in the form of diverticulitis and diverticular bleeding occur in approximately $10-15 \%$ of patients $[4,5]$. The incidence of diverticulitis increases with age with a mean age of 63 years at presentation [6]. Recent studies have suggested either equal gender distribution or a minor female preponderance [7].

Unlike diverticulitis, which predominantly involves the left colon, the right colon is the source of diverticular bleeding in $50-90 \%$ of patients $[8,9]$. Colonic diverticular bleeding occurs mainly in older patients with comorbid conditions, and the combined morbidity and mortality rates from the disease are approximately $10-20 \%[9,10]$.

Gastrointestinal symptoms are common among patients with renal failure, approaching $80 \%$ in dialysis patients [11]. Most features of diverticular disease, including presentation, and management, are similar in those with and without renal failure. However, compared to those without renal impairment, the disease may occur at a younger age (less than 40 years) and may be more severe in patients with renal dysfunction [12]. Complications, such as perforation, are associated with a higher mortality rate, and patients may have a higher rate of bleeding resulting from iatrogenic anticoagulation and/ or platelet dysfunction [13]. Compelling evidence suggests that treatment of diverticular disease complications in patients 
Table 1. Demographic and Baseline Characteristics of Patients With Symptomatic Diverticular Disease

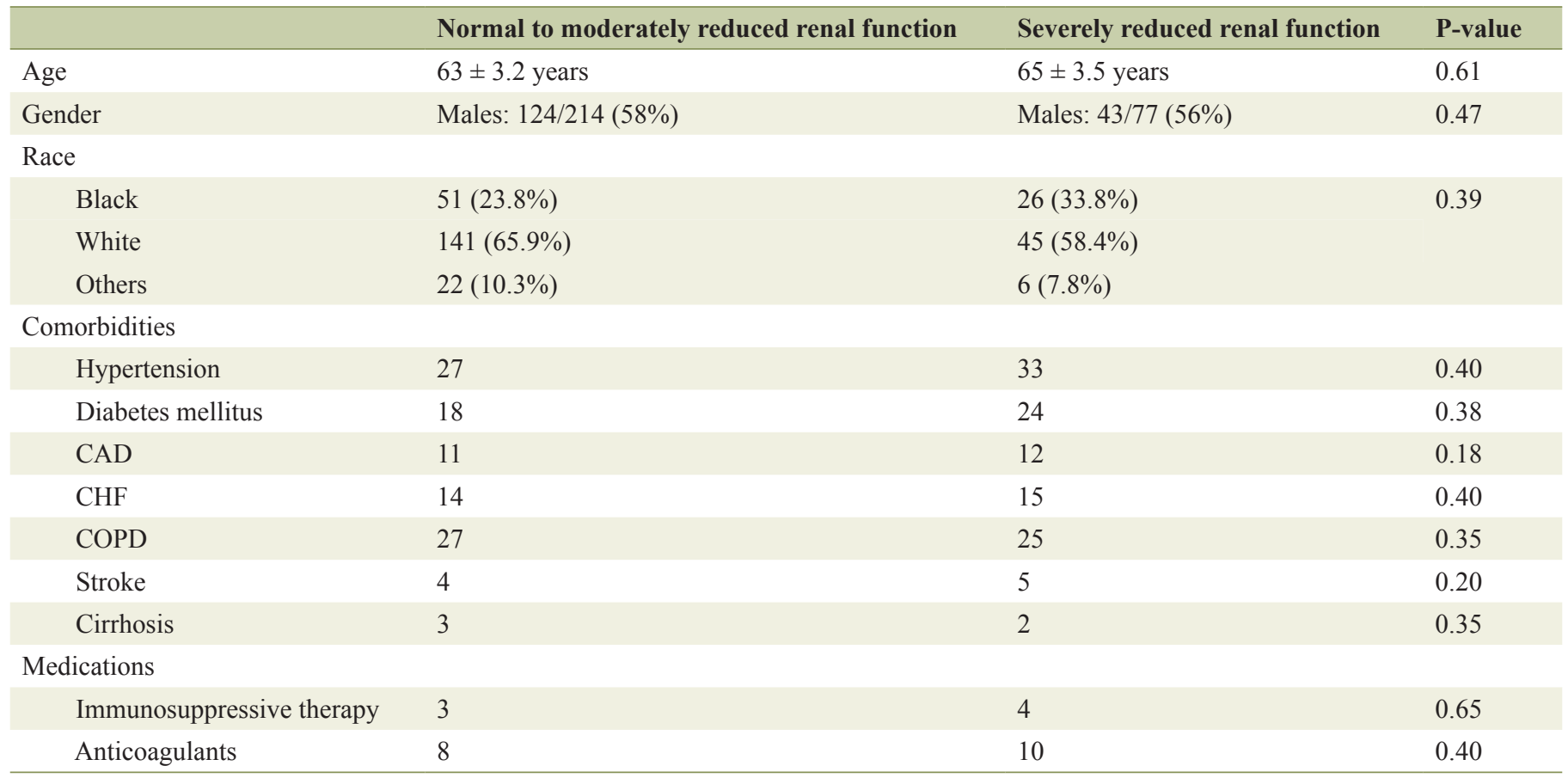

with renal disease frequently necessitates longer hospitalization, and invasive interventions including surgery $[14,15]$.

In this study, we examined the association between the baseline glomerular filtration rate (GFR) as a marker of renal function and the outcome of symptomatic diverticular disease in a single center retrospective cohort.

\section{Materials and Methods}

\section{Setting}

This study was conducted at an urban teaching acute care healthcare facility in northeastern USA. The study was approved by the institutional review board (IRB) of the facility.

\section{Study design and subjects}

We retrospectively reviewed records of all patients with a primary diagnosis of diverticulitis or diverticular bleeding treated at our hospital from January 1, 2011 to July 31, 2016. Excluded from the study were patients with incidental diagnosis of diverticular disease. Electronic charts of 2,109 patients admitted to our center with colonic diverticular disease were identified. Of these, 291 patients were found to have confirmed diagnosis of diverticulitis or diverticular bleeding.

Patients were evaluated to determine age, gender, race, medications, comorbidities, baseline GFR ( $\left.\mathrm{mL} / \mathrm{min} / 1.73 \mathrm{~m}^{2}\right)$, presenting complains, length of stay (LOS), computed tomography and colonoscopy reports, presence of colonic perfora- tions or abscesses, blood transfusion requirements, and in-hospital mortality. Based on the revised chronic kidney disease (CKD) classification (KDIGO. Summary of recommendation statements. Kidney Int. 2013;3(Suppl):5) and the revised chronic kidney disease (CKD) classification (American Diabetes Association: Diabetes Care. Vol. 30, Supplement 1, 2007), patients with GFR $\geq 30 \mathrm{~mL} / \mathrm{min} / 1.73 \mathrm{~m}^{2}$ (CKD stages 1, 2, and 3 ) were clustered at one side as a control group and those with GFR $<30 \mathrm{~mL} / \mathrm{min} / 1.73 \mathrm{~m}^{2}$ (CKD stages 4 and 5) constituted the study population.

\section{Statistical analysis}

Interval data were tested for fit-to-normality by the D'Agostino-Pearson omnibus normality test. Data which did not distribute normally were subjected to the appropriate nonparametric methods; otherwise parametric methods for groupwise comparisons were used. Normally distributed interval data were expressed as mean \pm standard deviation (SD); nonnormally distributed interval data were presented as median and interquartile range (IQR). Univariate categorical data were evaluated for significance by using the Chi-squared test or Fisher's exact test as appropriate. Covariates were chosen based on $P$ value of $\geq 4 \alpha(0.20)$ and were included in a binary logistic regression model which considered only significant interactions.

Because of the retrospective nature of the study, the odds ratio (OR) and 95\% confidence interval (95\% CI) were used as the measure of effect size. All inferences regarding statistical significance were based on a $\mathrm{P}$-value $<0.05$ on a twosided basis. Analyses were performed using Prism ${ }^{\circledR}$ software 
Table 2. Characteristics of Patients with Complicated Diverticulitis

\begin{tabular}{|c|c|c|c|}
\hline & GFR $\geq 30 \mathrm{~mL} / \mathrm{min} / 1.73 \mathrm{~m}^{2}$ & GFR $<30 \mathrm{~mL} / \mathrm{min} / 1.73 \mathrm{~m}^{2}$ & P-value \\
\hline Age & $55 \pm 3$ years & $65 \pm 4$ years & 0.24 \\
\hline Gender & Males: $20 / 31(65 \%)$ & Males: $7 / 13(54 \%)$ & 0.59 \\
\hline \multicolumn{4}{|l|}{ Race } \\
\hline Black & $5(16 \%)$ & $3(23 \%)$ & 0.95 \\
\hline White & $23(74 \%)$ & $8(62 \%)$ & \\
\hline Total & $31 / 136(23 \%)$ & $13 / 26(50 \%)$ & Odds ratio: $3.4 ; 95 \%$ confidence interval: $1.423-8.06 ; \mathrm{P}=0.0073$ \\
\hline
\end{tabular}

(GraphPad Corp., San Diego, CA) or SPSS ${ }^{\circledR}$ version 22.0 (IBM Corp., Armonk, NY).

\section{Results}

\section{Demographic and baseline characteristics}

Demographic and baseline characteristics in the study group (severely reduced renal function) and control group (normal to moderately reduced renal function) are illustrated in Table 1.

\section{Complicated diverticulitis and transfusion requirement}

Perforations or abscesses complicating diverticulitis developed in $31 / 136(23 \%)$ of patients with GFR $\geq 30 \mathrm{~mL} / \mathrm{min} / 1.73 \mathrm{~m}^{2}$, and in $13 / 26(50 \%)$ of patients with GFR $<30 \mathrm{~mL} / \mathrm{min} / 1.73 \mathrm{~m}^{2}$ (OR: 3.4; 95\% CI: 1.423 - 8.06; $\mathrm{P}=0.0073$ ). Mean age for patients with perforations or abscess was $55 \pm 3$ years in the GFR $\geq 30 \mathrm{~mL} / \mathrm{min} / 1.73 \mathrm{~m}^{2}$ group and $65 \pm 4$ years in $\mathrm{GFR}<30 \mathrm{~mL} /$ $\mathrm{min} / 1.73 \mathrm{~m}^{2}$ group $(\mathrm{P}=0.24)$. Race differences were not statistically different between the two groups $(\mathrm{P}=0.76)$ (Table 2$)$.

Blood transfusion for diverticular bleeding was required in $11 / 78(14 \%)$ of patients with GFR $\geq 30 \mathrm{~mL} / \mathrm{min} / 1.73 \mathrm{~m}^{2}$ and in $22 / 51(43 \%)$ of patients with GFR $<30 \mathrm{~mL} / \mathrm{min} / 1.73 \mathrm{~m}^{2}$ (OR: 4.6; 95\% CI: 1.99 - 10.76; $\mathrm{P}=0.0004$ ). Among patients who needed transfusion, mean age was $71 \pm 3.4$ years in GFR $\geq 30 \mathrm{~mL} / \mathrm{min} / 1.73 \mathrm{~m}^{2}$ group and $71 \pm 2.4$ years in those with GFR $<30 \mathrm{~mL} / \mathrm{min} / 1.73 \mathrm{~m}^{2}(\mathrm{P}=0.2)$. Race differences were not statistically significant between the two groups $(\mathrm{P}=0.79)$
(Table 3).

The associated comorbidities and other possible confounders are studies as in Figure 1. It showed the OR and 95\% $\mathrm{CI}$ for the association of severely reduced renal function (GFR $<30 \mathrm{~mL} / \mathrm{min} / 1.73 \mathrm{~m}^{2}$ ) with occurrence of abscess or perforation (Fig. 1a), and with transfusion requirement (Fig. 1b).

\section{LOS}

The mean LOS for patients with uncomplicated diverticulitis (localized diverticular inflammation with no associated abscess, fistula, obstruction, or perforation), patients with complicated diverticulitis (diverticular inflammation associated with an abscess, fistula, or perforation), and patients with diverticular bleeding in the GFR $\geq 30 \mathrm{~mL} / \mathrm{min} / 1.73 \mathrm{~m}^{2}$ group, and the GFR $<30 \mathrm{~mL} / \mathrm{min} / 1.73 \mathrm{~m}^{2}$ group are shown in Table 4.

\section{Discussion}

In general, the demographic features of patients with severely reduced kidney function who develop symptomatic diverticular disease are not significantly different from those with normal to moderately impaired renal function. Salamone et al presented similar findings when evaluated patients with endstage renal disease (ESRD) or renal transplantation and symptomatic diverticular disease [16].

The results of this retrospective cohort study show that the incidence of diverticulitis is higher in elderly population irrespective of the degree of renal impairment. Our observations

Table 3. Characteristics of Patients With Diverticular Bleeding With Transfusion

\begin{tabular}{|c|c|c|c|}
\hline & GFR $\geq 30 \mathrm{~mL} / \mathrm{min} / 1.73 \mathrm{~m}^{2}$ & GFR $<30 \mathrm{~mL} / \mathrm{min} / 1.73 \mathrm{~m}^{2}$ & P-value \\
\hline Age & $71 \pm 3.4$ years & $71 \pm 2.4$ years & 0.26 \\
\hline Gender & Males: 8/11 (73\%) & Males: $14 / 22(64 \%)$ & 0.23 \\
\hline Black & $3(27 \%)$ & $6(27 \%)$ & 0.25 \\
\hline White & $6(55 \%)$ & $13(59 \%)$ & \\
\hline
\end{tabular}


a

Abcess or Perforation

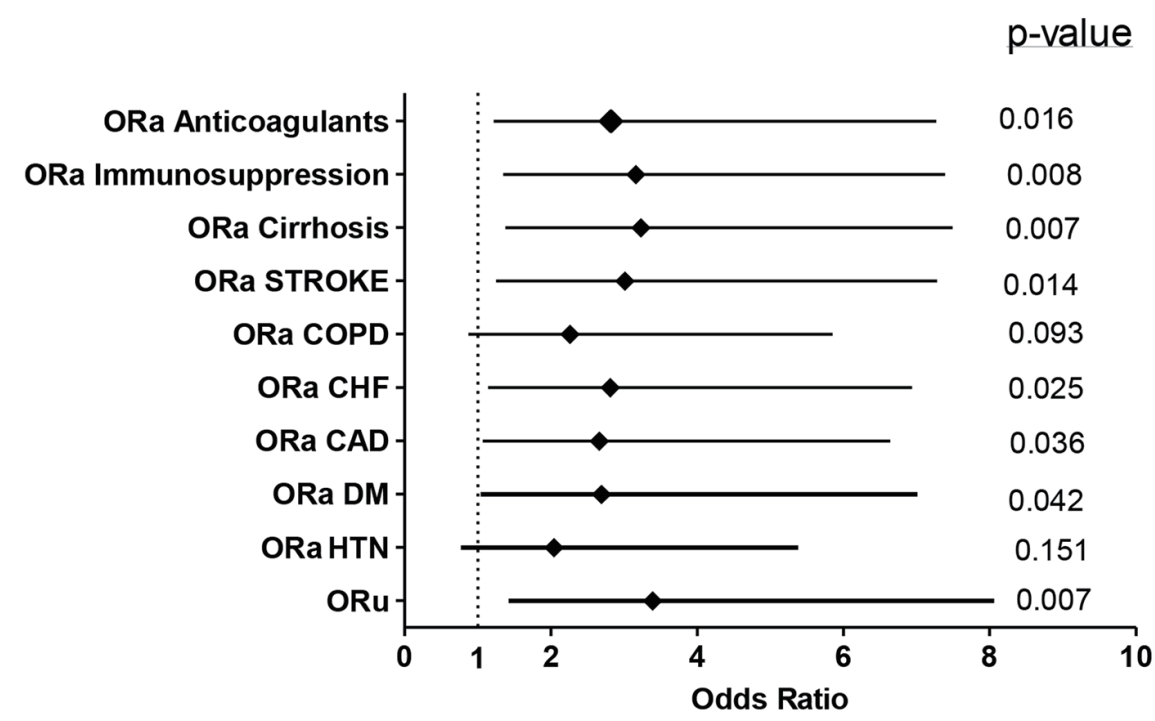

b

Transfusion

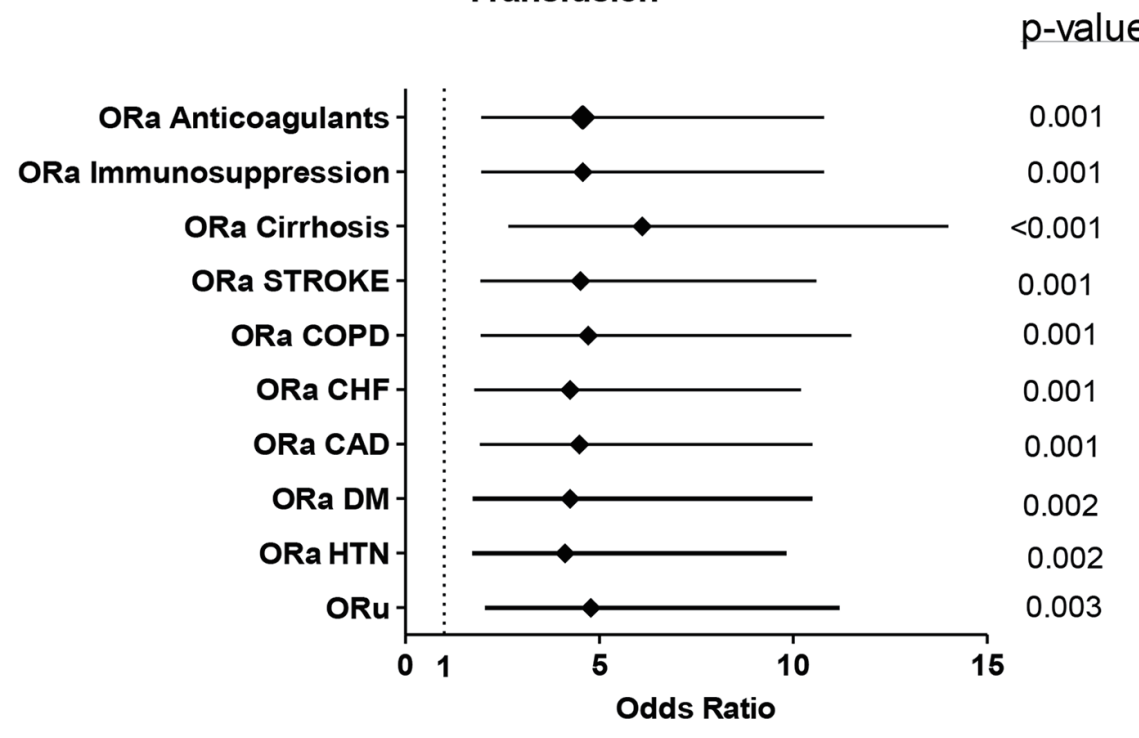

Figure 1. Forest plots showing the $\mathrm{OR}$ and $95 \% \mathrm{Cl}$ for the association of impaired renal function (GFR $<30 \mathrm{~mL} / \mathrm{min} / 1.73 \mathrm{~m}{ }^{2}$ ) with abscess or perforation (a) and with transfusion requirement (b). The univariate $\mathrm{OR}, \mathrm{ORu}$, is provided, along with the adjusted $\mathrm{OR}$ (ORa) for each of the covariates indicated.

are consistent with those of previous reports regarding the role of increasing age in diverticulitis. Although a slight increase in the incidence of diverticular disease in younger patients was observed during the last decade [17], Blachut et al reported that colonic diverticular disease is a significant problem in elderly patients, in both females and males [18]. Comparato et al reported that individuals younger than 40 years rarely suffer from diverticulitis, and the incidence increases to $65 \%$ in people older than 65 years [19].

Complications from diverticulitis such as perforations and abscesses develop at higher rates in patients with severely reduced kidney function. This is also consistent with results of previous reports. Chang et al reported that patients with ESRD has higher incidence of acute colonic diverticulitis, higher rates of surgical interventions and mortality [20]. Morris et al studied the incidence of perforated diverticulitis and risk factors for death in a UK population. The study found a higher mortality rate in those with pre-existing renal impairment [21]. Wang et al proposed that the immunosuppression status in patients with ESRD together with the alteration in colonic microflora and mucosal barrier disruption are the main mechanisms for gut bacterial translocation [22]. Klarenbeek et al worked to identify patients who might benefit from elective sigmoid resection after a conservatively treated episode of diverticuli- 
Table 4. Length of Stay for the Different Study Groups

\begin{tabular}{llll}
\hline & GFR $\geq \mathbf{3 0} \mathbf{~ m L} / \mathbf{m i n} / \mathbf{1 . 7 3} \mathbf{~ m}^{\mathbf{2}}$ & GFR $<\mathbf{3 0} \mathbf{~ m L} / \mathbf{m i n} / \mathbf{1 . 7 3} \mathbf{~ m}^{\mathbf{2}}$ & P-value \\
\hline Uncomplicated diverticulitis & $2.9 \pm 1.9$ & $5.8 \pm 2.7$ & $<0.0001$ \\
Complicated diverticulitis (perforations/abscesses) & $6.3 \pm 4$ & $8.5 \pm 4.4$ & 0.0001 \\
Diverticular bleeding without transfusion requirement & $3.1 \pm 1.5$ & $4.5 \pm 3.6$ & 0.03 \\
Diverticular bleeding with transfusion requirement & $8.5 \pm 2.5$ & $9 \pm 5$ & 0.04 \\
\hline
\end{tabular}

tis. The study concluded that elective resection of the sigmoid colon might be justified in high-risk patients, including those with chronic renal failure [23].

The incidence of diverticular bleeding in patients with ESRD is known to be similar to that of the general population (except for patients with adult polycystic kidney disease (APKD) on regular dialysis who have a higher incidence of diverticular bleeds) $[24,25]$. Our study shows that there is a higher rate of blood transfusion requirement and an increased length of hospital stay in patients with severely reduced kidney function than in those with normal to moderate renal dysfunction. A Japanese case-control study by Niikura et al reported an OR of 6.4 for diverticular hemorrhage in patients with chronic kidney failure [26]. Ryota et al identified chronic renal failure as a risk factor for diverticular bleeding [26]. In patients with chronic renal failure, intestinal blood vessels are involved by the generalized systemic arteriosclerosis. Furthermore, the heparin used in dialysis, and platelet dysfunction also represent additional risk factors for diverticular bleeding in this group of patients $[27,28]$.

Our study has some limitations. We have not studied the presence of other confounding factors that may affect the outcome of symptomatic diverticular disease such as patients' lifestyle, dietary habits, and smoking history.

\section{Conclusions}

Symptomatic diverticular disease is predominantly a disease of the elderly population. The results of this study provide valuable information regarding the effect of severely reduced renal function on the outcome of symptomatic diverticular disease. The higher rates of complicated diverticulitis, transfusion requirements for diverticular bleeding, and length of hospital stay in patients with severely reduced kidney function compared to patients with normal to moderately reduced renal function, clarify why this group of patients should be treated carefully.

\section{Grant Support}

None.

\section{Financial Disclosures}

None.

\section{Conflicts of Interest}

None.

\section{References}

1. Everhart JE, Ruhl CE. Burden of digestive diseases in the United States part II: lower gastrointestinal diseases. Gastroenterology. 2009;136(3):741-754.

2. Shaheen NJ, Hansen RA, Morgan DR, Gangarosa LM, Ringel Y, Thiny MT, Russo MW, et al. The burden of gastrointestinal and liver diseases, 2006. Am J Gastroenterol. 2006;101(9):2128-2138.

3. Peery AF, Barrett PR, Park D, Rogers AJ, Galanko JA, Martin CF, Sandler RS. A high-fiber diet does not protect against asymptomatic diverticulosis. Gastroenterology. 2012;142(2):266-272 e261.

4. Strate LL, Modi R, Cohen E, Spiegel BM. Diverticular disease as a chronic illness: evolving epidemiologic and clinical insights. Am J Gastroenterol. 2012;107(10):14861493.

5. Shahedi K, Fuller G, Bolus R, Cohen E, Vu M, Shah $\mathrm{R}$, Agarwal N, et al. Long-term risk of acute diverticulitis among patients with incidental diverticulosis found during colonoscopy. Clin Gastroenterol Hepatol. 2013;11(12):1609-1613.

6. Etzioni DA, Mack TM, Beart RW, Jr., Kaiser AM. Diverticulitis in the United States: 1998-2005: changing patterns of disease and treatment. Ann Surg. 2009;249(2):210-217.

7. Parks TG. Natural history of diverticular disease of the colon. Clin Gastroenterol. 1975;4(1):53-69.

8. Wong SK, Ho YH, Leong AP, Seow-Choen F. Clinical behavior of complicated right-sided and left-sided diverticulosis. Dis Colon Rectum. 1997;40(3):344-348.

9. Gostout CJ, Wang KK, Ahlquist DA, Clain JE, Hughes RW, Larson MV, Petersen BT, et al. Acute gastrointestinal bleeding. Experience of a specialized management team. J Clin Gastroenterol. 1992;14(3):260-267.

10. Uden P, Jiborn H, Jonsson K. Influence of selective mesenteric arteriography on the outcome of emergency surgery for massive, lower gastrointestinal hemorrhage. A 15-year experience. Dis Colon Rectum. 1986;29(9):561566.

11. Hammer J, Oesterreicher C, Hammer K, Koch U, Traindl O, Kovarik J. Chronic gastrointestinal symptoms in hemodialysis patients. Wien Klin Wochenschr. 1998;110(8):287-291. 
12. Abramson SJ, Berdon WE, Laffey K, Ruzal-Shapiro C, Nash M, Baer J. Colonic diverticulitis in young patients with chronic renal failure and transplantation. Pediatr Radiol. 1991;21(5):352-354.

13. Galbraith P, Bagg MN, Schabel SI, Rajagopalan PR. Diverticular complications of renal failure. Gastrointest Radiol. 1990;15(3):259-262.

14. Dalla Valle R, Capocasale E, Mazzoni MP, Busi N, Benozzi L, Sivelli R, Sianesi M. Acute diverticulitis with colon perforation in renal transplantation. Transplant Proc. 2005;37(6):2507-2510.

15. Tranaeus A, Heimburger O, Granqvist S. Diverticular disease of the colon: a risk factor for peritonitis in continuous peritoneal dialysis. Nephrol Dial Transplant. 1990;5(2):141-147.

16. Salamone, Louis Frank. Outcomes in Patients with EndStage Renal Disease and Colonic Diverticular Disease. Yale Medicine Thesis Digital Library. 2009:454.

17. Weizman AV, Nguyen GC. Diverticular disease: epidemiology and management. Can J Gastroenterol. 2011;25(7):385-389.

18. Blachut K, Paradowski L, Garcarek J. Prevalence and distribution of the colonic diverticulosis. Review of 417 cases from Lower Silesia in Poland. Rom J Gastroenterol. 2004;13(4):281-285.

19. Comparato G, Pilotto A, Franze A, Franceschi M, Di Mario F. Diverticular disease in the elderly. Dig Dis. 2007;25(2):151-159.

20. Chang SS, Huang N, Hu HY. Patients with end-stage renal disease were at an increased risk of hospitalization for acute diverticulitis. Medicine (Baltimore). 2016;95(39):e4881.

21. Morris CR, Harvey IM, Stebbings WS, Hart AR. Incidence of perforated diverticulitis and risk factors for death in a UK population. Br J Surg. 2008;95(7):876-881.

22. Wang F, Jiang H, Shi K, Ren Y, Zhang P, Cheng S. Gut bacterial translocation is associated with microinflammation in end-stage renal disease patients. Nephrology (Carlton). 2012;17(8):733-738.

23. Klarenbeek BR, Samuels M, van der Wal MA, van der Peet DL, Meijerink WJ, Cuesta MA. Indications for elective sigmoid resection in diverticular disease. Ann Surg. 2010;251(4):670-674.

24. Junquera F, Feu F, Papo M, Videla S, Armengol JR, Bordas JM, Saperas E, et al. A multicenter, randomized, clinical trial of hormonal therapy in the prevention of rebleeding from gastrointestinal angiodysplasia. Gastroenterology. 2001;121(5):1073-1079.

25. Scheff RT, Zuckerman G, Harter H, Delmez J, Koehler R. Diverticular disease in patients with chronic renal failure due to polycystic kidney disease. Ann Intern Med. 1980;92(2 Pt 1):202-204.

26. Niikura R, Nagata N, Akiyama J, Shimbo T, Uemura N. Hypertension and concomitant arteriosclerotic diseases are risk factors for colonic diverticular bleeding: a casecontrol study. Int J Colorectal Dis. 2012;27(9):1137-1143.

27. Bischel MD, Reese T, Engel J. Spontaneous perforation of the colon in a hemodialysis patient. Am J Gastroenterol. 1980;74(2):182-184.

28. Iseki K, Kinjo K, Kimura Y, Osawa A, Fukiyama K. Evidence for high risk of cerebral hemorrhage in chronic dialysis patients. Kidney Int. 1993;44(5):1086-1090. 